Ann. Geophysicae 16, 721-730 (1998) @ C EGS - Springer-Verlag 1998

\title{
Typical disturbances of the daytime equatorial $F$ region observed with a high-resolution HF radar
}

\author{
E. Blanc ${ }^{1}$, E. Houngninou ${ }^{2}$ \\ ${ }^{1}$ Laboratoire de Detection et de Géophysique, Commissariat à l'Energie Atomique, Bruyères le Chatel, France \\ Fax: + 01692670 23; e-mail: blanc@ldg. bruyeres.cea.fr \\ ${ }^{2}$ Département de physique, Université d'Abidjan, Ivory Coast
}

Received: 18 December 1996 / Revised: 30 January 1998 / Accepted: 4 February 1998

\begin{abstract}
HF radar measurements were performed near the magnetic equator in Africa (Korhogo $9^{\circ} 24^{\prime} 63^{\prime \prime} \mathrm{N}$ $5^{\circ} 37^{\prime} 38^{\prime \prime} \mathrm{W}$ ) during the International Equatorial Electrojet Year (1993-1994). The HF radar is a high-resolution zenithal radar. It gives ionograms, Doppler spectra and echo parameters at several frequencies simultaneously. This paper presents a comparative study of the daytime ionospheric structures observed during 3 days selected as representative of different magnetic conditions, given by magnetometer measurements. Broad Doppler spectra, large echo width, and amplitude fluctuations revealed small-scale instability processes up to the F-region peak. The height variations measured at different altitudes showed gravity waves and larger-scale disturbances related to solar daytime influence and equatorial electric fields. The possibility of retrieving the ionospheric electric fields from these Doppler or height variation measurements in the presence of the other possible equatorial ionospheric disturbances is discussed.
\end{abstract}

\section{Introduction}

Electric fields and plasma drifts are essential parameters for understanding the dynamics of the $\mathrm{E}$ and $\mathrm{F}$ regions of the ionosphere. At the magnetic equator, their motion is controlled by the vertical and zonal electric fields arising from the low-latitude dynamo current system (Matsushita, 1969). The global-scale motion of winds across the magnetic field lines generates a dynamo system formed by currents and polarization electric fields. The E-region dynamo fields are created by tidal winds in the E layer, and are coupled to the F-region by equipotential magnetic lines. F-region dynamo fields are driven by F-region winds. During daytime the latter are

Correspondence to: E. Blanc largely reduced by the conductivity of E-region, but are important at night (Kelley, 1989; Fejer, 1991). The intense E-region east-west electric field at 100-110 km (Richmond, 1973) induces a vertical plasma motion throughout the equatorial F-region at a $\mathbf{E} \times \mathbf{B}$ velocity, where $\mathbf{E}$ and $\mathbf{B}$ are the electric field and the magnetic field, respectively. The ionospheric drifts were intensively studied over the last three decades using VHF Jicamarca incoherent-scatter radar at $50 \mathrm{MHz}$ (Basley and Woodman, 1969; Fejer 1986, 1991) and the general characteristics of plasma drifts and ionospheric electric fields with their dependence on season, solar cycle, and magnetic activity were determined (Fejer et al., 1979). A prereversal peak in the upward velocity at evening is a most common feature during solar cycle maximum years (Woodman, 1970). This is due to the very rapid decrease in the E-region conductivity after sunset compared to that of the F-region (Farley et al., 1986). Ionospheric drift measurements with coherent HF radar were performed using Doppler spectra or echo height changes with time. The latter method is often limited to the evening period (Subbarao and Krishna Murthy, 1994; Jayachandran et al., 1993) when the F-region bottom altitude rises beyond $300 \mathrm{~km}$. The importance of the recombination and profile changes is then lower and the apparent vertical displacement velocity is about the same as the vertical $\mathbf{E} \times \mathbf{B}$ plasma drift velocity (Bittencourt and Abdu, 1981). This paper presents a new set of HF radar measurements performed during daytime from sunrise to sunset in the F-region at several radar frequencies with high time and height resolution. These measurements have been used for determining the influence of different kind of disturbances on $\mathbf{E} \times \mathbf{B}$ plasma drift velocity measurements. The experiments were performed near the West African magnetic equator, in a large altitude range from the lower part of the $\mathrm{F} 1$ region up to the $\mathrm{F} 2$ layer during several days, chosen as representative of magnetically quiet and disturbed conditions. The radar experiment is described in the first part of the paper, observations are presented in a second part, and the third part is devoted to a discussion about 
the possibility of using these data for ionospheric electric field measurements and about the influence of the other equatorial ionospheric disturbances on these measurements.

\section{Radar measurements}

The radar measurements were performed in West Africa at Korhogo-Ivory-Coast $\left(9^{\circ} 24 \mathrm{~N}, 5^{\circ} 37 \mathrm{~W}\right.$, dip $\left.4^{\circ} \mathrm{S}\right)$, in the period of March-July 1993, during the participation of the Laboratoire de Détection et de Géophysique of the Commissariat à I'Energie Atomique (France) to the International Equatorial Electrojet Year (IEEY).

The LDG radar is a vertical HF radar. It operates in a main radar mode on four frequencies simultaneously, chosen in the range $1-30 \mathrm{MHz}$. It provides in a large height range HF echoes parameters and Doppler spectra. A second mode gives ionograms with sweep frequency sounding. All radar parameters can be selected according to the experiment purposes. The antennas for transmission and reception are two spiral logarithmic antennas (100-m diameter). Their radiation diagram is almost omnidirectional with, however, a gain of $10 \mathrm{~dB}$ in the vertical direction. Ionospheric reflections, then arise mainly from the vertical direction, but the radar is also able to receive reflections or scattering from oblique directions. Echoes can be analyzed by range and Doppler measurements. In addition a complementary network of 7 loop antennas is used for echolocation. Three antennas are located at distances of 20,40 , and $80 \mathrm{~m}$ from one reference antenna both in north-south and east-west directions. This system is equivalent to three superimposed antenna basis: a small, a medium, and a large one used alternatively for avoiding phase aliasing. The radar transmits successively two pulses of $10-\mu \mathrm{s}$ width seperated by $\mu$ s on two different frequencies. This permits to perform two radar modes in parallel, and to reach an increased time resolution of $70 \mathrm{~ms}$ if all radar modes are used simultaneously. The height resolution determined by the pulse length is $1.5 \mathrm{~km}$. The peak pulse power is $5 \mathrm{~kW}$. The pulse repetition frequency is 100 or $200 \mathrm{~Hz}$.

Three days of measurements have been selected as representative of different conditions: 21 and 30 May 1993 were both very quiet days (the sum of the magnetic index $\Sigma \mathrm{km}$ for each day was 6 and 9, respectively), 27 May 1993 was a disturbed day $(\Sigma \mathrm{km}=24)$ following five of the most quiet days of May. A first rapid analysis of the radar data revealed also that 30 May was submitted to a significant gravity wave activity.

The present observations were obtained with a radar mode providing information over a whole day. Doppler spectra were obtained with a time repetition of $10 \mathrm{~min}$ and a time integration of 10-30 s. They are measured with a height increment of $2.5 \mathrm{~km}$ over $600 \mathrm{~km}$. The echoes amplitudes, for the four radar frequencies, are measured in parallel over $900 \mathrm{~km}$ with a height increment of $0.6 \mathrm{~km}$. Plasma frequency reflections were obtained in the $\mathrm{F}$ region at different altitudes from 150 to $600 \mathrm{~km}$ with three radar frequencies in the range
4-9 MHz. The fourth frequency, generally selected between 2 and $3 \mathrm{MHz}$, gives only E-region reflections during daytime. Ionograms are provided by the $\mathrm{HF}$ radar and by the CNET ionosonde located at the same station, they give the electron density profile every 15 min using the inversion POLAN program (Titheridge, 1985).

\section{Observations}

The time variations of the F-region velocity deduced from the Doppler data on a radar frequency close to $8 \mathrm{MHz}$ are shown in Fig. 1 for 21, 27, and 30 May 1993 from 07.30 to $20.00 \mathrm{LT}$. The echoes arise from the upper part of the $F$ region at virtual heights of about 400 to $500 \mathrm{~km}$. The velocity presents weak variations for all the selected days. The velocity does not exceed $15 \mathrm{~m} / \mathrm{s}$ either downward or upward. The amplitude of these oscillations on 30 May 1993 is slightly greater as compared with the other two days. At sunset (18.00-20.00 LT) the vertical motion is directed upward with a pronounced enhancement of the velocity, especially on 27 May and 30 May. A comparison between these three diagrams does not reveal much difference between magnetically quiet and disturbed days.

The F-region radar data are characterized by broad spectra shapes and large echo widths. An example of the variations of the Doppler spectra with the height, obtained with a radar frequency of $8.3 \mathrm{MHz}$ on 21 May 1993 at 13:57:36 LT is shown in Fig. 2. The Doppler sign changes from positive values in the lower
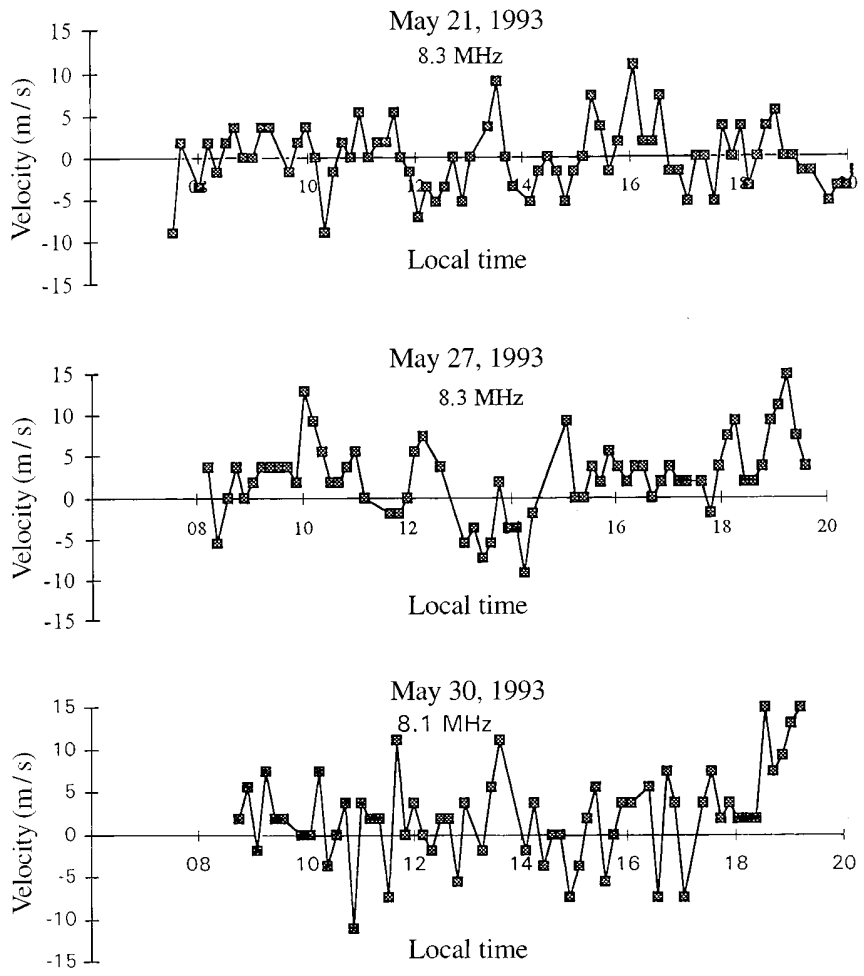

Fig. 1. Vertical velocities deduced from Doppler measurements in the upper F region during daytime on 21, 27, 30 May 1993 
height range (542-546 km) to negative values at greater heights $(554-560 \mathrm{~km})$. As the height resolution deduced from the pulse width was $1.5 \mathrm{~km}$, this suggests the presence of electron density irregularities moving close to the plasma frequency reflection level and which are able to produce partial reflections below the reflection level or oblique reflections. Figure 3 shows typical fluctuations of the echo amplitude measured on the three radar frequencies at the same time. Irregularities produce fluctuations with a time-period of a few seconds at the lower altitude $(180 \mathrm{~km})$ up to a few tens of seconds at the higher altitude of observation $(300 \mathrm{~km})$. They produce also an increase of the echo width of $40 \mathrm{~km}$ at $250 \mathrm{~km}$ to $15 \mathrm{~km}$ at $440 \mathrm{~km}$ corresponding to $10-12 \mathrm{~km}$ at $180-300 \mathrm{~km}$ after ionogram inversion. The period of observation of these irregularities is correlated with that of the irregularities in the electrojet region (Blanc et al., 1996). Similar amplitude fluctuations are never observed in the evening, when the E-region irregularities disappear or in the morning before they appear.

Characteristic large-scale variations of the echo height were obtained simultaneously. Figure 4 shows the results obtained on 21 May 1993 at three different radar frequencies $(4.5,6.6$, and $8.5 \mathrm{MHz})$ for quiet magnetic conditions. The most striking effect is the

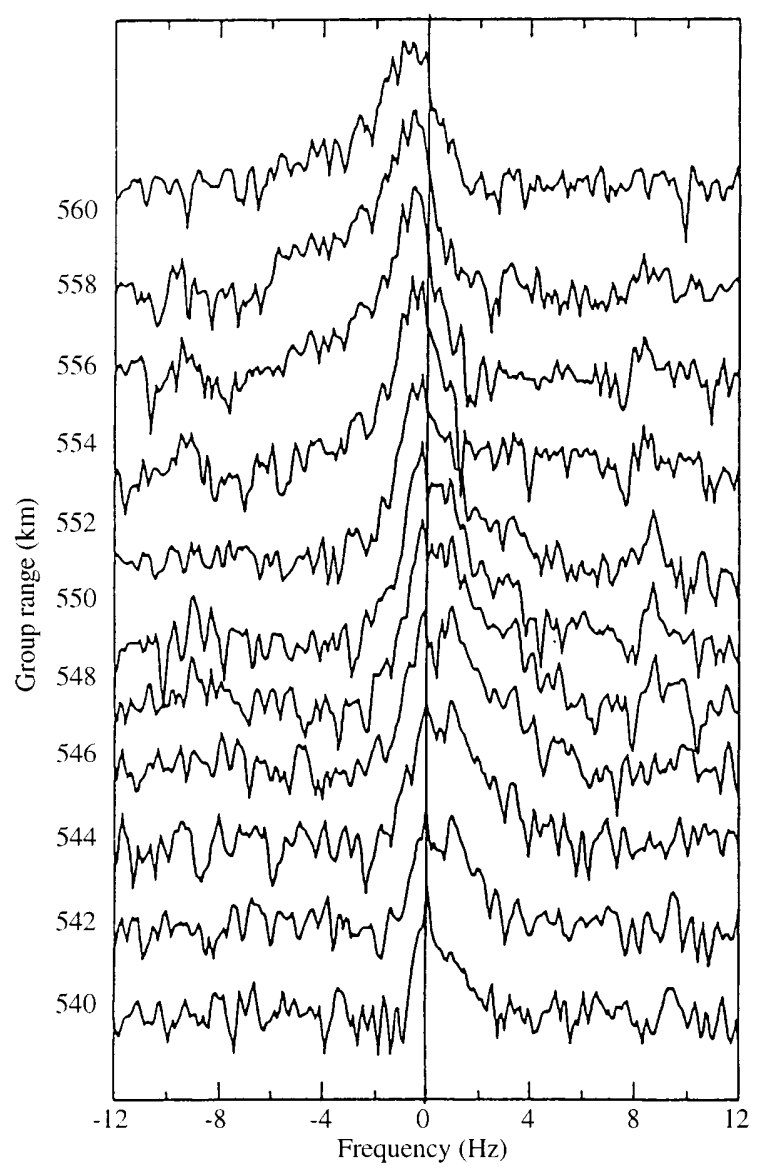

Fig. 2. Examples of spectra obtained on 21 May 1993 at 13.57 LT near the plasma frequency reflection level in the upper $\mathrm{F}$ region, showing the motion of irregularities difference in the behavior of the lower $\mathrm{F}$ region, observed with the lower frequency $4.5 \mathrm{MHz}$ and presenting a minimum at noon, and the upper $\mathrm{F}$ region observed with the highest frequency $8.5 \mathrm{MHz}$ and presenting a maximum at noon. This motion is however not symmetrical and the echoes at $4.5 \mathrm{MHz}$ suddenly rise in the period 13.30-14.30 LT in the afternoon while the morning descent lasts $4 \mathrm{~h}$ from 09.00 to $13.00 \mathrm{LT}$. In the upper $\mathrm{F}$ region the echo height presents a maximum at $12.00 \mathrm{LT}$. The intermediate frequency $6.6 \mathrm{MHz}$ showed a slight height increase in the morning followed by a height decrease in the evening. Height fluctuations with time-scales of several minutes are also observed on all radar frequencies.

Figure 5 shows the virtual and real vertical velocities corresponding to the observations of Fig. 4 . The virtual vertical velocities have been deduced from the virtual height changes in the time and the real velocities have been determined from real height variations given by inverted ionograms taken every $15 \mathrm{~min}$. The upper part of the figure indicates the corresponding variations of the critical frequency of the $F 1$ and $F 2$ regions of the ionosphere. The period of observation (at a lower radar frequency) of the E-region irregularities, characterized by typical type-II spectra, is indicated by a horizontal dotted line. The variations of the magnetic field component $\mathrm{H}$ recorded at the same station (Vassal et al., 1998) are shown at the bottom of the figure. The expected altitude variation produced by the solar zenith angle changes and by the daytime evolution of the photoionization presents a minimum at noon. This variation has been observed at the lower radar frequency $4.5 \mathrm{MHz}$. It appears as negative velocities in the morning and positive velocities in the afternoon. The virtual velocity increase of about $15 \mathrm{~m} / \mathrm{s}$ in the early afternoon at 13.00-1500 LT corresponds to a retardation effect from an ionization increase in the lower regions, and it disappears in the real velocity variations. An upward real motion at $10 \mathrm{~m} / \mathrm{s}$ only remains in the real velocity diagrams at $17.00 \mathrm{LT}$. In the upper $\mathrm{F}$ region, the velocity measured at $8.3 \mathrm{MHz}$ is about $20 \mathrm{~m} / \mathrm{s}$ in the morning, and falls off from positive to negative at noon. The positive phase of the upper F-region velocity is correlated to the increase in the magnetic field in the morning. The virtual velocity is reduced when the magnetic field is maximum, and becomes negative when the magnetic field decreases. The variations of the real velocity are similar but lower by a factor of about 2 in the morning, they are close to zero in the evening.

On 30 May 1993 (Fig. 6) in quiet magnetic conditions, strong height oscillations were observed in the whole altitude range with periods in the range 10$30 \mathrm{~min}$. The oscillations appear slightly later when the frequency and then the height decreases, showing a downward phase velocity. The amplitude (peak to peak) of the height fluctuation is about $30 \mathrm{~km}$. These waves are characteristic of ionospheric disturbances produced by gravity waves. The downward phase velocity, measured at $13.00 \mathrm{LT}$ in altitudes ranging from 240 to $280 \mathrm{~km}$, is about $80 \mathrm{~m} / \mathrm{s}$. Similar oscillations were also apparent on 21 May but with weaker amplitudes. The 
May 21, $1993-14.50$ LT

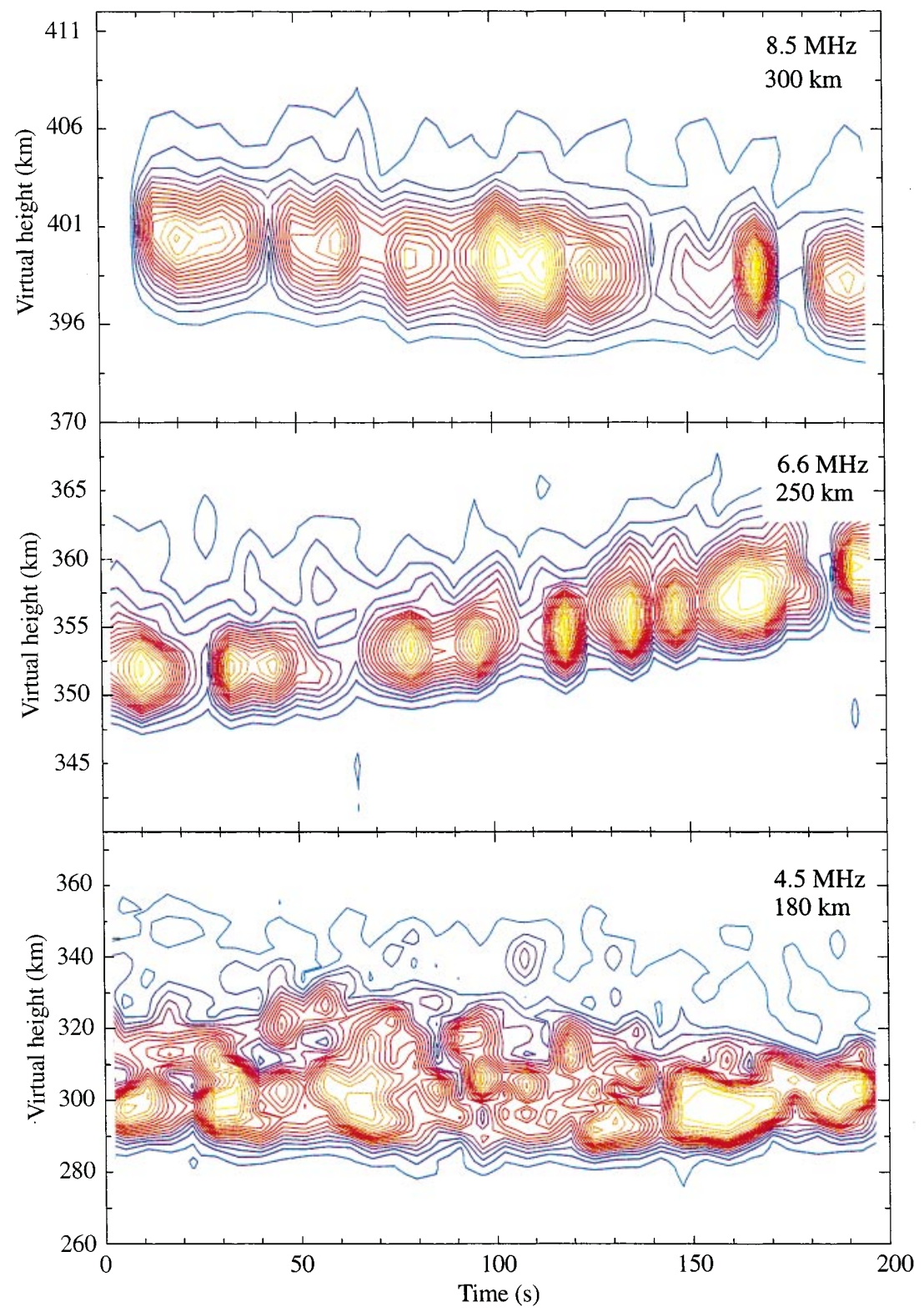

Fig. 3. Example of echo fluctuations observed on 21 May 1993 at 14.00 LT on three different radar frequencies. Reflection altitudes and radar frequencies are indicated in the right upper part of each diagram radar frequency $4.8 \mathrm{MHz}$ showed also shorter-period oscillations at 14.00-16.00 LT which do not appear on 6.5 and $8.1 \mathrm{MHz}$. The large daytime height variation of the upper $\mathrm{F}$ layer presents a maximum at noon and is roughly comparable to that of 21 May but the main maximum occurs later (14.00 instead of $12.00 \mathrm{LT}$ ). The second maximum does not exist or is masked by the gravity wave activity. As on 21 May the data obtained in the lower $\mathrm{F}$ region at $4.8 \mathrm{MHz}$ showed a slow height decrease in the morning with a minimum at 12.00-13.00 LT and a sudden height increase in the afternoon at 13.00 LT about $1 \mathrm{~h}$ earlier than on 21 May.

Figure 7, similar to Fig. 5, shows the virtual and real velocities deduced from the virtual and real height changes, the F1- and F2-region critical frequencies and the corresponding magnetic field variations. The maximum of the virtual velocity (about $30 \mathrm{~m} / \mathrm{s}$ ) observed at
14.00 LT at 4.8 MHz in the lower F region is produced by a retardation of the radar wave due to an increase in ionization at lower altitudes as it disappears in the real velocities. In the upper $\mathrm{F}$ region, the vertical velocities measured at $8.1 \mathrm{MHz}$ in the morning are correlated with the morning magnetic field increase and the virtual velocity sign changes from positive to negative when the magnetic field decreases at about $14.00 \mathrm{LT}$. The real velocities are weaker in the morning about $5 \mathrm{~m} / \mathrm{s}$, close to zero in the afternoon, and increase up to $10 \mathrm{~m} / \mathrm{s}$ in the evening. The E-region irregularities were continuously observed from 08.00 to $17.00 \mathrm{LT}$.

Figure 8 shows a third radar diagram obtained on 27 May 1993 in disturbed magnetic conditions and Fig. 9 displays the corresponding virtual and real velocities with the critical frequencies and magnetic field variations. The top of the $\mathrm{F}$ region undergoes a strong 


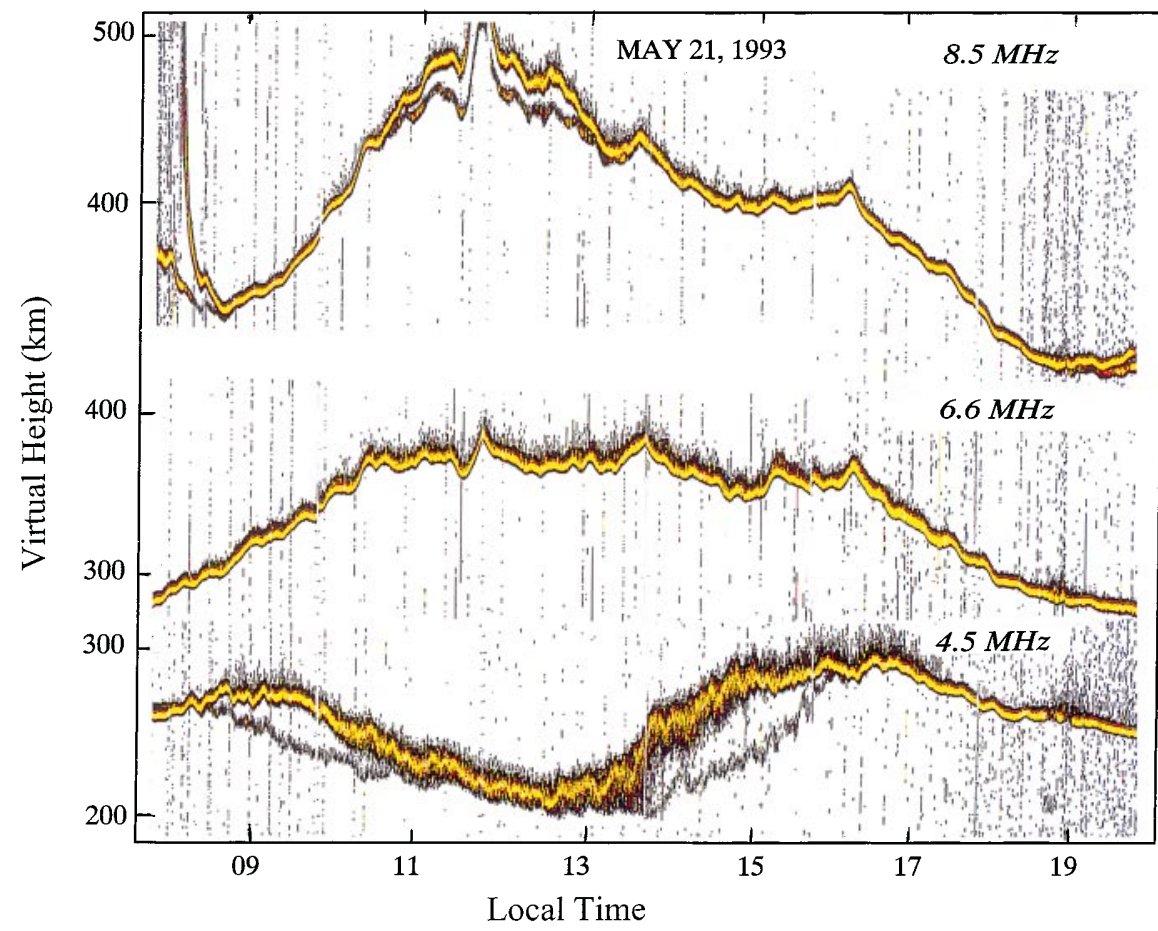

Fig. 4. HF echo fluctuations observed in the daytime $F$ region of the ionosphere on 21 May 1993 on three different radar frequencies
May 21, 1993

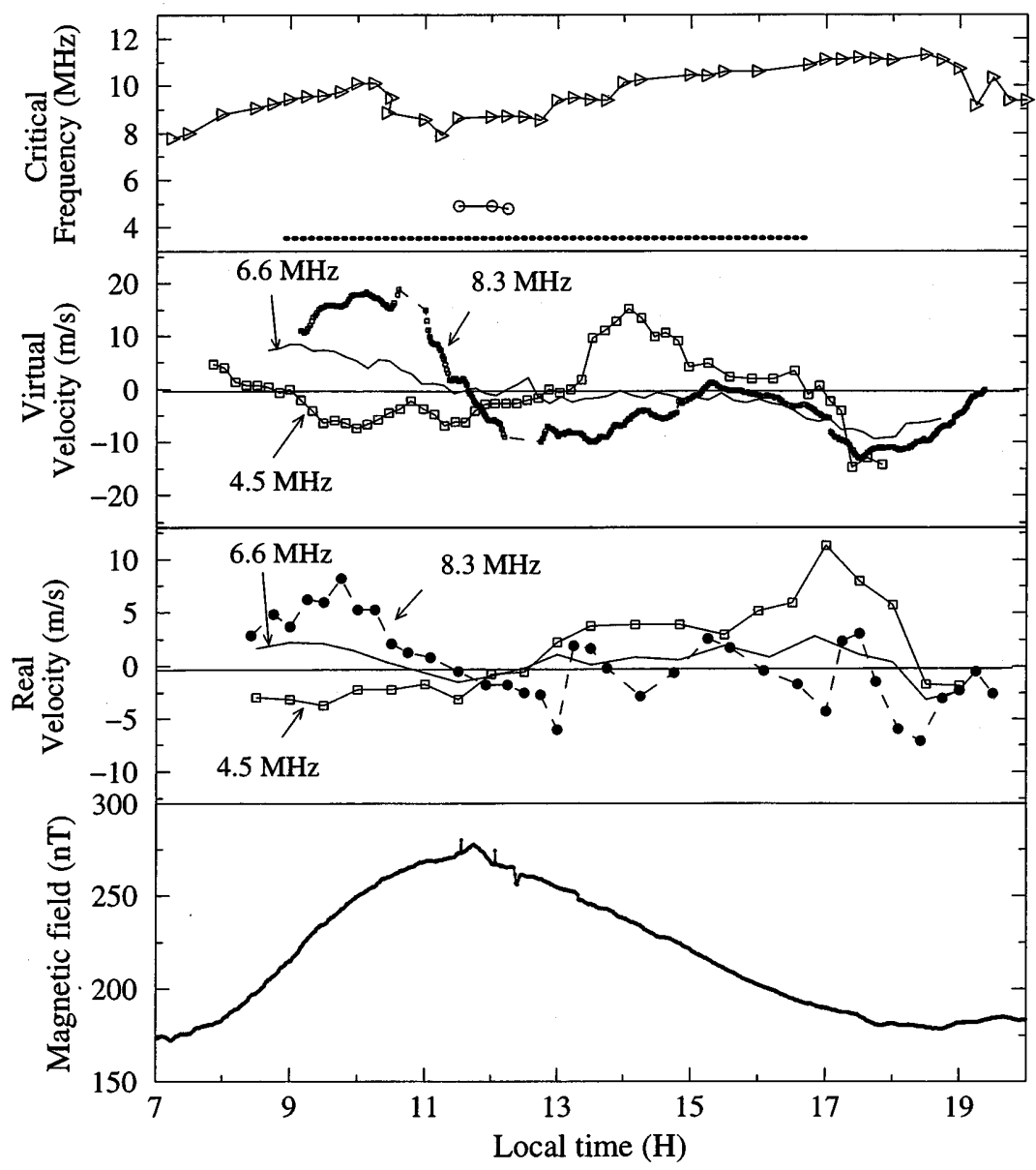

Fig. 5. Comparison between the F-region virtual and real velocity, deduced from the height-time changes, and the variations of the $\mathrm{H}$ component of the magnetic field. The velocities obtained with the highest and lowest radar frequency correspond to reflections in the upper and lower $\mathrm{F}$ region, respectively. The values of the $\mathrm{F} 1$ and $\mathrm{F} 2$ critical frequencies of the ionosphere are represented in the top diagram (by circles and triangles, respectively) and the observation period of the E-region irregularities is indicated by a horizontal dotted line 


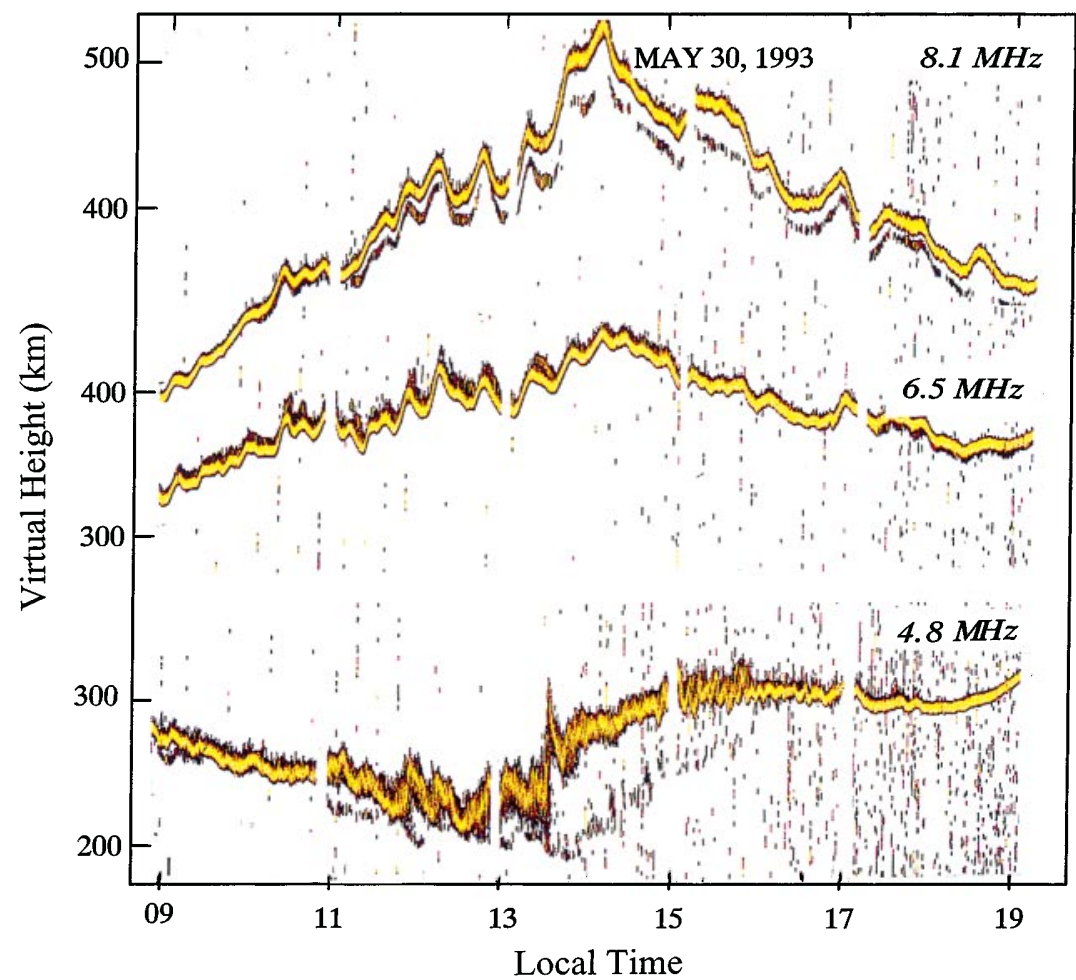

May 30, 1997

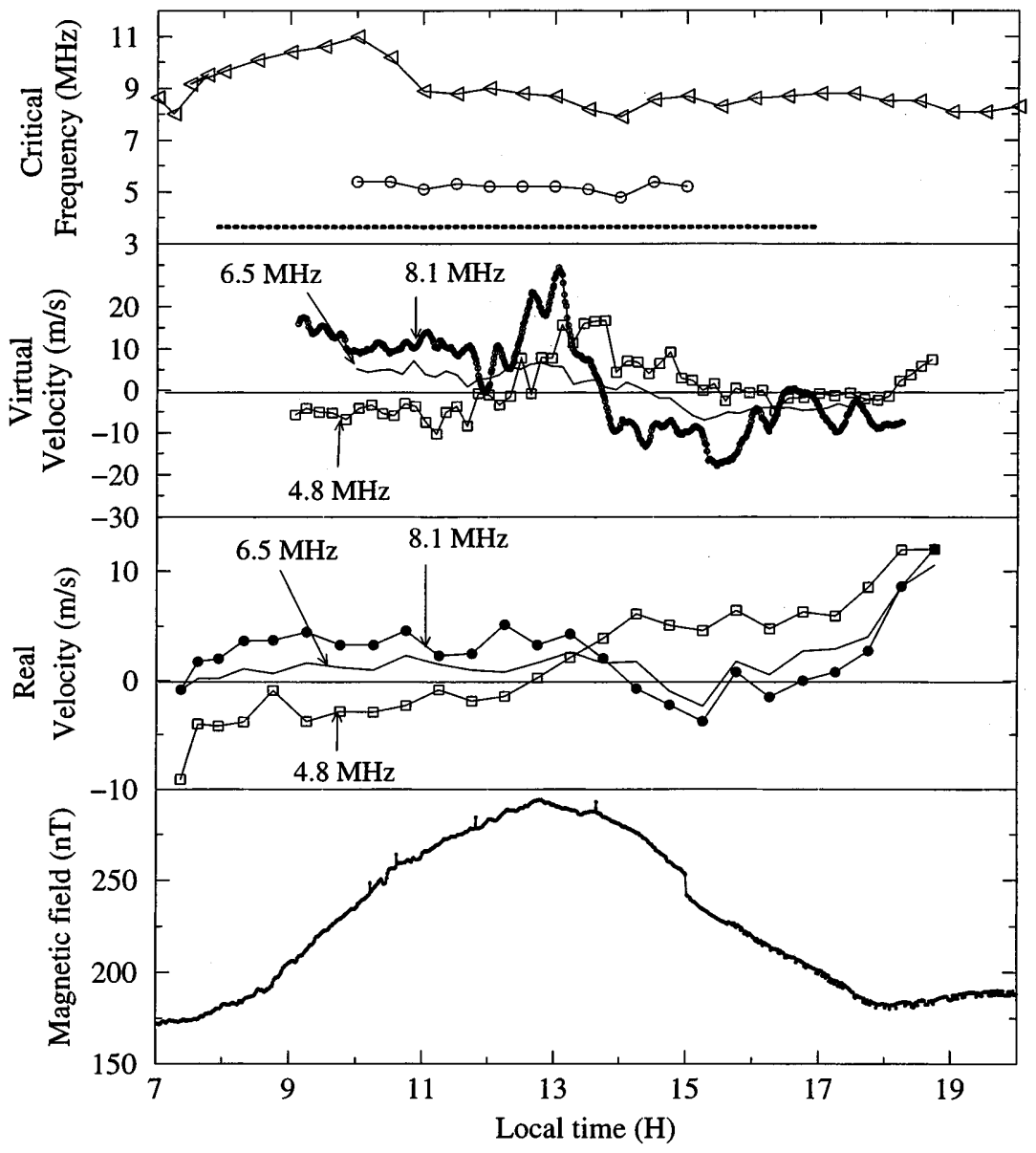

Fig. 6. As Fig. 4 for 30 May 1993

Fig. 7. As Fig. 5 for 30 May 1993 
upward variation between 08.00 and 13.00 LT from 300 to $500 \mathrm{~km}$ followed by a sudden reverse motion with a great slope down at 13.00 from 500 to $400 \mathrm{~km}$ within $1 \mathrm{~h}$. The motion inverts again at 19.00 LT and the layer rises at sunset. This upward F-region motion is typical and precedes the appearance of the night spread F. The results obtained in the lower $F$ region are comparable to those of the other days, but the afternoon velocity increase is much weaker and an upward velocity is observed at 17.00-18.00 LT.

\section{Discussion}

In this paper we report radar daytime measurements taken during the IEEY in Ivory Coast with the LDG $\mathrm{HF}$ radar in the $\mathrm{F}$ region. The behavior of the $\mathrm{F}$ region has been analyzed at very different time- and heightscales using different radar parameters and different radar frequencies in parallel.

At the smallest scales, irregularities have been shown up by Doppler and radar echo measurement. These irregularities produce changes in the F-region Doppler spectra, varying from positive to negative values in the lower and upper parts of the echoes. This effect is correlated with echo amplitude fluctuations from about 10 at $180 \mathrm{~km}$ up to several tens of seconds at $300 \mathrm{~km}$. The origin of these fluctuations can be related to electron densities irregularities near the plasma frequency reflection level, producing partial reflections just below the reflection level or oblique reflections. Irregularities have also been analyzed during this same radar campaign with a high time and height resolution mode adapted to the study of small-scale structures (Blanc et al., 1996). Irregularities are characterized by time variations of less than $1 \mathrm{~s}$ and by a kilometric heightscale in the E region and by larger time- and heightscales in the $\mathrm{F}$ region. F-region irregularities exist when irregularities are also present in the E region. Echolocation measurements showed that echoes on these irregularities arise both from vertical and oblique reflections in the east-west direction. The use of several radar frequencies allowed to locate them close to the reflection level as the Doppler frequency shift was proportional to the radar frequency (Blanc et al., 1996). These irregularities are difficult to observe on the ionograms as they just appear as an increase in the echo width of few tens of kilometers. The Doppler spectra were obtained in the present experiment with a short integration time of 10s. This time-range is comparable or lower than the time fluctuation of the irregularities in the upper $\mathrm{F}$ region, these spectra are thus representative of the small-scale fluctuations rather than large-scale motions, which would only be observable by using larger integration times.

At large time-scales, the most typical observed disturbances are the gravity waves. They are believed to be the main cause of wind and temperature fluctuations and play an important role in the dynamic of the upper atmosphere. Their origin is related to cold fronts, convective meteorological motions, thunderstorms, cyclones, or to magnetic activity. At equatorial latitudes, gravity waves play an important role in the formation of the equatorial spread F (Hysell et al., 1990). They were frequently observed in the present experiments. Their amplitude is variable from day to day and does not depend on the magnetic conditions. The gravity wave activity was specially strong on 30 May, in magnetic

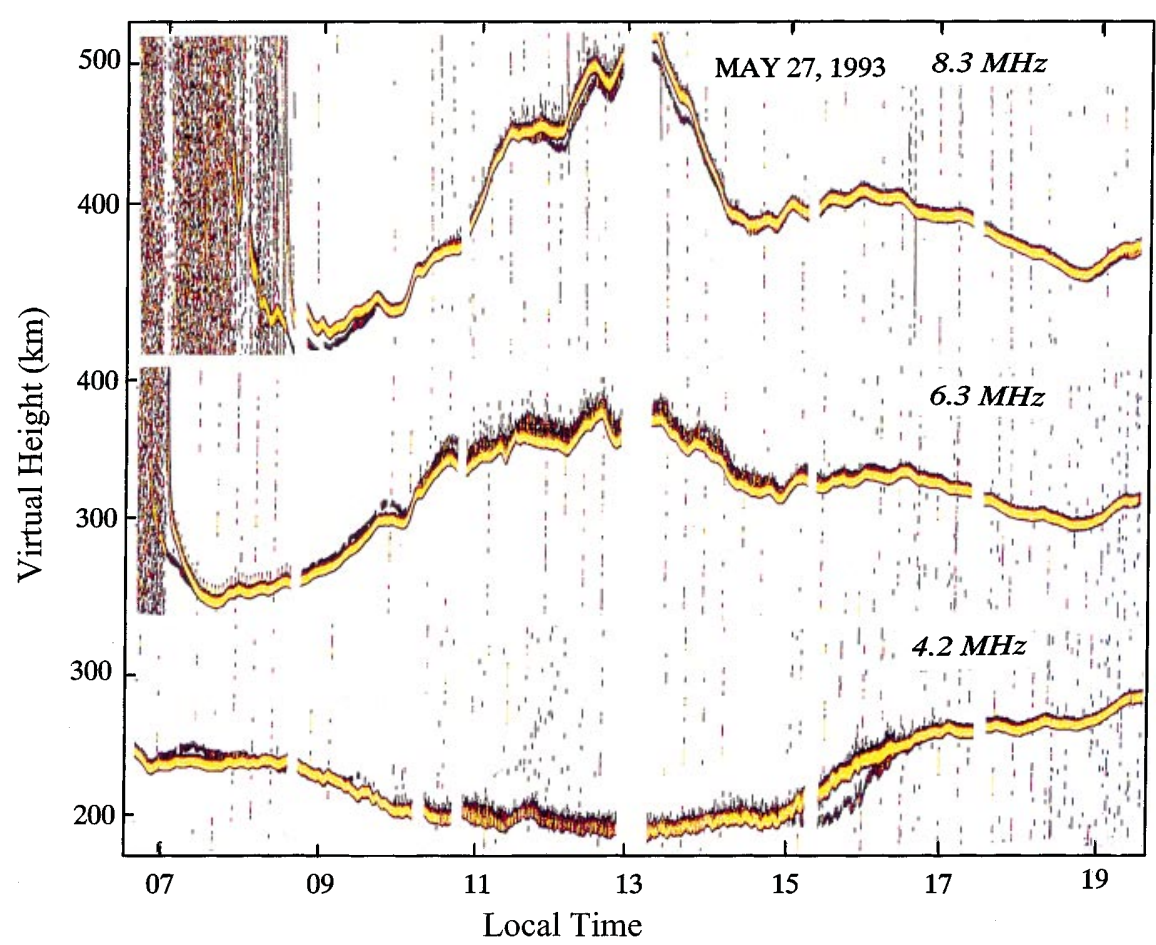

Fig. 8. As Fig. 4 for 27 May 1993 
May 27, 1993

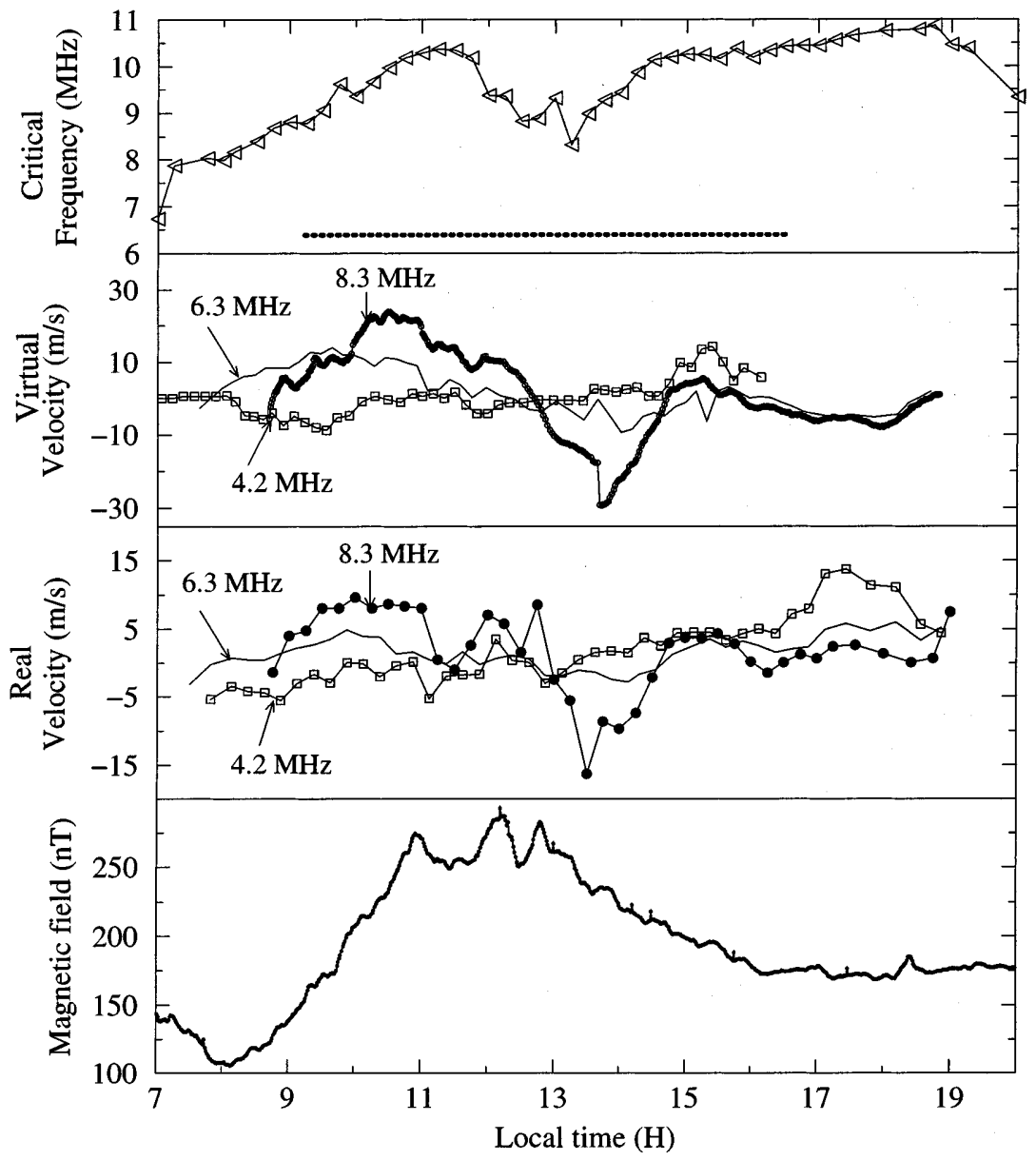

Fig. 9. As Fig. 5 for 27 May 1993 quiet conditions (Fig. 6). The wave characteristics are periods in the range 5-30 min, and a downward phase velocity of the order of $80 \mathrm{~m} / \mathrm{s}$ at altitudes of 240 $280 \mathrm{~km}$, appearing as a phase delay at lower radar frequencies, hence at lower altitudes. Oscillations with shorter periods of about 6-8 min were also observed on 30 May at 15-16 LT at the lowest radar frequency $4.8 \mathrm{MHz}$ at $180 \mathrm{~km}$. This period is shorter than the Brunt-Väisälä period of about 9-10 min at the observation altitude (Francis, 1975). These waves may be explained as acoustic waves. They no longer appear on the $6.5 \mathrm{MHz}$ echoes at $260 \mathrm{~km}$. This suggests that their origin is tropospheric. Indeed, upwardly propagating waves are damped by viscosity and thermal conductivity. They reach higher altitude levels for longer wave periods. The atmosphere is then comparable to a filter for upwardly propagating waves, only long-period waves being able to reach the upper $\mathrm{F}$ region (Blanc, 1985). Another interpretation for these oscillations could be considered as gravity waves observed with an increased frequency, due to a wind-produced Doppler shift (Vincent et al., 1997). The absence of these same gravity waves simultaneously at an altitude $80 \mathrm{~km}$ higher is however difficult to explain, gravity waves being generally observed by the radar over very large altitude ranges.
Larger-scale motions of the $\mathrm{F}$ region are mainly induced by daytime solar changes and electric field variations. The behavior of the lower and upper $\mathrm{F}$ region are quite different in the virtual height diagrams where the lower F-region virtual height decreases in the morning and increases in the evening while the upper $\mathrm{F}$ region is submitted to an inverted motion. The upper Fregion upward and downward motion is correlated with the magnetic field increase and decrease.

The expected solar effect is a decrease in the layer height in the morning followed by an increase in the evening because of the solar zenith angle variation changes. At noon the vertical solar radiation penetrates deeper into the atmosphere and produces ionization at lower altitudes. This effect is observed in the lower F region where the vertical velocity is negative in the morning and positive in the evening. The strong virtual velocity increase in the early afternoon on 21 May and on 30 May, is a retardation effect produced on the radar measurements by an ionization increase below the reflection level and it does not correspond to a real ionospheric motion of the $\mathrm{F}$ region. The general motion of the lower $\mathrm{F}$ region is thus mainly controlled by the solar zenith angle variation.

The motion of the upper $F$ region is different. For the three days considered the velocities are positive in the 
morning, the upward virtual velocities are higher than the real velocities, obtained after ionogram inversion (Figs. 5, 7, 9), by a factor of about 2 . The real velocities vary from a day to another from about $5 \mathrm{~m} / \mathrm{s}$ in magnetically quiet days (30 and 21 May) to $10 \mathrm{~m} / \mathrm{s}$ on the disturbed day (27 May). This motion last up to about $12.00 \mathrm{LT}$. The velocities are higher at the highest measurement altitudes. For the three days considered the motion is inverted in the afternoon and the F-region virtual velocity is negative. The real velocities are very weak (21 May) or negative in the early afternoon (on 27 May at $14.00 \mathrm{LT}$ and on 30 May at $15.00 \mathrm{LT}$ ). In the evening the dominant F-region motion is a height increase. This height increase appeared on 30 May in the whole considered height range with higher velocities in the lower $\mathrm{F}$ region. The $\mathrm{F}$ region rises also on 27 May but this motion is weaker in the lower $\mathrm{F}$ region. This evening F-region height increase has not been observed on 21 May, a magnetically very quiet day.

The dynamic of the $\mathrm{F}$ region is controlled by the $\mathrm{E}$ region electric fields. The daytime eastward electric field produces an upward plasma motion at the origin of the equatorial fountain (Kelley, 1989). As the electric field is maximum at noon, the upward plasma motion is also expected to be the most intense at noon.

In the morning, an upward motion clearly appears in the vertical velocity measurements for the three considered days but with a larger one on 27 May. The velocity is larger at the highest altitudes $(260-280 \mathrm{~km})$ than lower $(220-240 \mathrm{~km})$. A gradient of $0.06 \mathrm{~m} / \mathrm{s} / \mathrm{km}$ was evaluated on 30 and 21 May, the gradient is higher $0.1 \mathrm{~m} / \mathrm{s} / \mathrm{km}$ on 27 May in magnetically disturbed conditions. Such gradients were also observed by Sastri et al. (1995) and Fejer et al. (1996).

In the early afternoon at $12.00-15.00 \mathrm{LT}$, the velocity measured in the upper $\mathrm{F}$ region is downward on 27 and 30 May. This inversion is not due to an inversion of the E-region electric field as the type-II instabilities, always observed during the same period, indicate an eastward electric field. The upward-moving plasma of the equatorial fountain diffuse along the magnetic field lines on north and south sides of the magnetic equator at higher latitudes, producing a trough in the F2-region densities and a decrease in the F-region critical frequency (Sambou et al., 1998). The result is an apparent downward motion of the isodensity altitude measured by radar. This motion is correlated with an upward plasma flow, as the E-region electric field remains eastward during the same period. Later in the afternoon at 15.00-17.00 LT the critical frequency increases when the fountain effect decreases. In the evening, upward velocities are measured on 27 and 30 May. This upward motion continued in the night up to $650 \mathrm{~km}$ at $02.00 \mathrm{LT}$ on 28 May and to $500 \mathrm{~km}$ at $22.00 \mathrm{LT}$ on 30 May. This height increase has been followed by spread F. Differently, on 21 May, the F-region height decreases in the night and spread F is not observed. Strong upward Fregion motion has already often been observed in the evening (Fejer et al., 1996; Jayachandran et al., 1993), and at this time the interpretation is easier in terms of electric field effect as the upward virtual velocity is directly related to the zonal electric field (Bittencourt and Abdu, 1981).

Acknowledgements. The authors thank the LDG team for setting up the LDG radar experiment during the IEEY, J. Vassal (ORSTOM) for providing the magnetic field data, Fleury (CNET) for giving ionograms measured by the Korhogo ionosonde. They thank also P. Vila for many stimulating and helpful discussions.

Topical Editor D. Alcaydé thanks J. Scali and another referee for their help in evaluating this paper.

\section{References}

Basley, B. B., and R. F. Woodman, On the control of the F region drift velocity by the $\mathrm{E}$ region electric field: experimental evidence, J. Geophys. Res., 31, 865-867, 1969

Bittencourt, J. A., and M. A. Abdu, A theoretical comparison between apparent and real vertical ionization drift velocities in the equatorial F region, J. Geophys. Res., 86, 2451-2454, 1981.

Blanc, E., Observations in the upper atmosphere of infrasonic waves from natural or artificial sources: a summary, Ann. Geophysicae, 3, 673-687, 1985.

Blanc, E., B. Mercandalli and E. Houngninou, Kilometric irregularities in the $\mathrm{E}$ and $\mathrm{F}$ regions of the daytime equatorial ionosphere observed by a high-resolution HF radar, Geophys. Res. Lett., 23, 645-648, 1996.

Farley, D. T., E. Bonelli, B. G. Fejer and M. F. Larsen, The prereversal enhancement of the zonal electric field in the equatorial ionosphere, J. Geophys. Res., 91, 13723-13728, 1986.

Fejer, B. G., Equatorial ionospheric electric fields associated with magnetospheric disturbances, (solar wind-magnetosphere coupling), Terra Science, Tokyo, 1986.

Fejer, B. G., Low-latitude electrodynamic plasma drift: a review. $J$. Atmos, Terr. Phys., 53, 677-693, 1991.

Fejer, B. G., D. T. Farley, R. F. Woodman, and C. Calderon, Dependence of equatorial $\mathrm{F}$ region vertical drifts on season and season and solar cycle, J. Geophys. Res., 84, 5792-5796, 1979.

Fejer, B. J., E. R. De Paula, L. Scherliess, and I. S. Balista, Incoherent scatter radar, ionosonde, and satellite measurements of equatorial $\mathrm{F}$ region vertical plasma drifts in the evening sector, Geophys. Res. Lett, 1733-1736, 1996.

Francis, S. H., Global propagation of atmospheric gravity wave: a review. J. Atmos. Terr. Phys., 37, 1011-1054, 1975.

Hysell, D. L., M. C. Kelley, W. E. Swartz, and R. F. Woodman, Seeding and layering of equatorial spread $\mathrm{F}$ by gravity waves, $J$. Geophys. Res., 95, 17253-17260, 1990.

Jayachandran, B., N. Balan, P. B. Rao, J. H. Sastri, and G. J. Bailey, HF Doppler and Ionosonde observations on the onset conditions of equatorial spread F, J. Geophys. Res., 1374113750, 1993.

Kelley, M. C., The earth's ionosphere, plasma physics and electrodynamics, Academic Press, 1989.

Matsushita, S., Dynamo currents, wind, and electric field, Radio Sci., 4, 771, 1969.

Richmond, A.D., Equatorial electrojet II. Use of the model to study the equatorial ionosphere, J. Atmos. Terr. Phys., 35, 1105-1118, 1973.

Sambou, E., P.M. Vila, and B. Jenkins, Non-trough f0F2 enhancements at near equatorial Dip latitudes, this issue, 1998.

Sastri, J. H., V. K. Meena Varna, and S. R. Prabhakaran Nayar, Height gradient of $\mathrm{F}$ region vertical drift in the evening equatorial ionosphere, Geophys. Res. Lett., 20, 2645-2648, 1995.

Subbarao, K. S. V., and B. V. Krishna Murthy, Post-sunset F-region vertical velocity variations at magnetic equator, J. Atmos. Terr. Phys., 56, 59-65, 1994.

Titheridge, J. E., Ionogram analysis with the generalized program POLAN, report UAG-93, NOAA Boulder, 1985. 
Vassal, J., M. Menvielle, Y. Cohen, M. Dukhan, and C. AmoryMazaudier, A study of the transient variation of the earth electromagnetic field at dip latitudes in western Africa (Mali and Ivory Coast), this issue, 1998.
Vincent, R. A., S. J. Allen, and S. D. Eckermann, Gravity wave parameters in the lower ionosphere. In Gravity wave processes, Ed. K. Hamilton, NATO ASI Series, 1997.

Woodman, R. F., Vertical drift velocities and east-west electric fields at the magnetic equator, J. Geophys. Res., 75, 6249-6259, 1970. 